\section{Congenital vascular malformations of the retina and choroid}

H Heimann and B Damato

\begin{abstract}
Purpose To review recent advances in the diagnosis and treatment of congenital vascular malformations of the retina and choroid. Methods Review of the current literature on retinal haemangioblastoma, racemose haemangiomatosis, retinal cavernous haemangioblastoma, circumscribed choroidal haemangioma, and diffuse choroidal haemangioma.

Conclusion The management of patients with congenital vascular lesions of the retina and choroid is advancing rapidly through recent developments in genetic testing, ocular imaging, and treatment. Most are associated with systemic disease, which may be lifethreatening. New therapeutic methods such as Verteporfin photodynamic therapy and antiangiogenic therapy have significantly improved the treatment of retinal and choroidal angiomas and vascular malformations. Ophthalmologists have a major role in detecting and diagnosing these tumours and in providing long-term care in collaboration with a specialist in the field.
\end{abstract} Eye (2010) 24, 459-467; doi:10.1038/eye.2009.310; published online 18 December 2009

Keywords: retinal haemangioblastoma; racemose haemangiomatosis; retinal cavernous haemangioblastoma; circumscribed choroidal haemangioma; diffuse choroidal haemangioma; photodynamic therapy

\section{Introduction}

Vascular tumours and malformations of the retina and choroid are rare and diverse. Most are associated with systemic disease, which may be life-threatening. The management of patients with these tumours is advancing rapidly, thanks to the developments in genetic testing, ocular imaging, and treatment. For these reasons, patients with vascular tumours and malformations are increasingly referred to a centre with an experienced multidisciplinary team and relevant expertise in therapeutic methods such as photodynamic therapy (PDT) and anti-angiogenic therapy. The management of these patients in specialised centres also enhances opportunities for research, thereby improving our understanding of the pathophysiology of these conditions and facilitating the evaluation of novel therapeutic methods. Nonetheless, ophthalmologists have a major role in detecting and diagnosing these tumours and in providing long-term care in collaboration with a specialist in the field.

In this article, we review recent advances in the diagnosis and treatment of congenital vascular malformations of the retina and choroid.

\section{Retinal haemangioblastoma}

Retinal haemangioblastomas (also known as capillary angiomas) are benign vascular retinal tumours that can occur sporadically or in association with von Hippel-Lindau (VHL) disease. ${ }^{1}$ They can develop at any age. Those associated with VHL disease are typically diagnosed at around 20 years of age (range, 3-47), whereas sporadic tumours present later in life, at around 30-40 years (range, $7-74$ ). ${ }^{1}$ The clinical appearances and associated symptoms vary according to the size and location of the lesion as well as any secondary effects. Small peripheral tumours are mostly asymptomatic and difficult to detect. They may resemble a microaneurysm or appear as a small coil of capillaries with a grey-orange colour and nondilated feeding and draining retinal vessels. With increasing size, these haemangioblastomas form orange-red vascular tumours within the retina and their feeder vessels enlarge. Larger lesions produce intra- and subretinal hard
Ocular Oncology Unit, Royal Liverpool University Hospital, Liverpool, UK

Correspondence: H Heimann, Ocular Oncology Unit, Royal Liverpool University Hospital

Prescot Street, Liverpool,

Merseyside L7 8XP UK

Tel: + 44151706 3970; Fax: + 44151706 5861; E-mail: heinrich.heimann@ gmail.com

Received: 4 November 2009 Accepted: 17 November 2009

Published online: 18 December 2009 
exudates, in the surrounding part of the fundus and at the macula, where circinate patterns may form (Figure 1). An epiretinal membrane may also develop. More advanced lesions give rise to vitreous bands, which cause tractional retinal detachment (Figure 2). Severe exudative retinal detachment can also occur. ${ }^{2}$ In the advanced stages of this disease, secondary glaucoma and uveitis commonly occur, resulting in a blind and painful eye. ${ }^{3}$

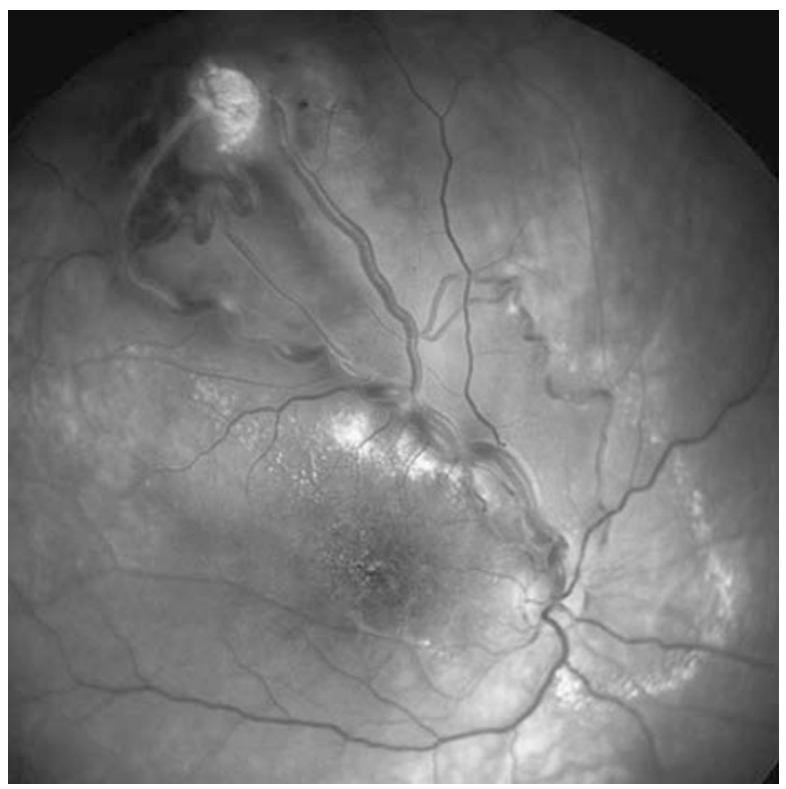

Figure 1 Retinal haemangioblastoma in a patient with von Hippel-Lindau disease. Dilated feeder vessels and exudative retina changes involving the macula can be seen.

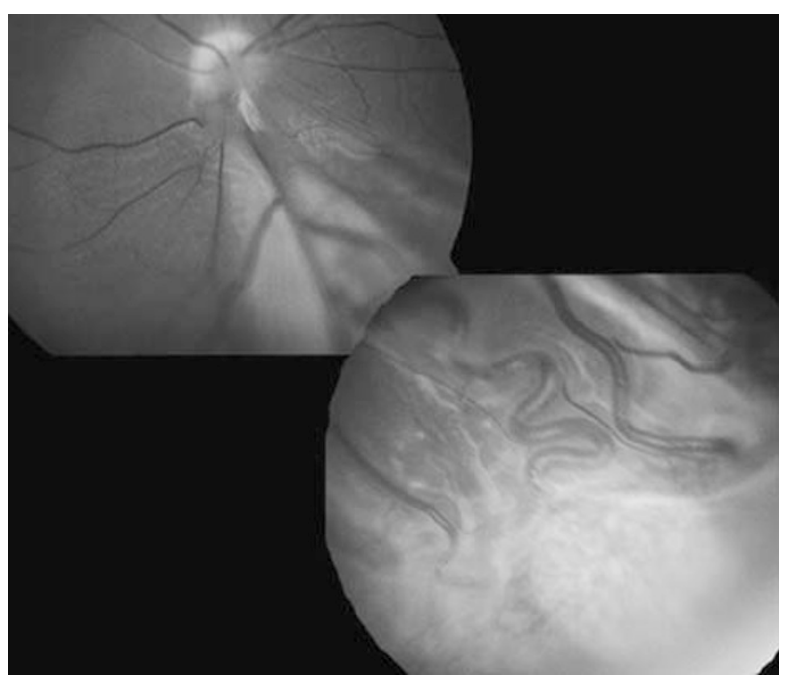

Figure 2 Advanced inferior retinal haemangioblastoma with tractional and exudative retinal detachment in a patient with von Hippel-Lindau disease.
Most retinal haemangioblastomas are located in the peripheral retina. About $15 \%$ arise at or around the optic nerve head. Juxtapapillary tumours appear as orangegrey intraretinal lesions with surrounding exudative changes and can easily be mistaken for parapapillary choroidal neovascularisation. ${ }^{4}$ Haemangioblastomas involving the optic disc are classified as endophytic if they grow towards the vitreous, exophytic if they extend towards the outer retina, and sessile if they show flat growth in the middle retinal layers. ${ }^{3}$ Histopathologically, these tumours are composed of small capillary-sized blood vessels with a normal endothelial lining, interstitial vacuolated stromal cells, and reactive gliosis. 5,6 They are thought to arise from small, perivascular, poorly differentiated cells with a scanty cytoplasm, known as 'tumorlet cells'.

VHL disease is inherited in an autosomal dominant manner with variable penetrance. It causes benign and malignant tumours and cysts in several organs. ${ }^{7}$ The disease is caused by mutations of the VHL gene on chromosome 3p25-26. ${ }^{8}$ Different types of mutations correlate with variations of the disease phenotype. Interestingly, in addition to vascular endothelial growth factor (VEGF) the tumour cells also show increased expression of hypoxia-induced factor, ubiquitin, erythropoietin, and the chemokine receptor CXCR4. ${ }^{5}$ In a large series of 327 patients published by Neumann et al, ${ }^{7}$ the most common lesions were haemangioblastoma of the central nervous system (52\% of affected patients), retinal haemangioblastoma $(48 \%)$, renal cysts $(33 \%)$, phaeochromocytoma (33\%), pancreatic cysts (22\%), and renal cell carcinoma (22\%). In addition, there can be endolymphatic sac tumours, which cause deafness, and papillary cystadenomas of the epididymis, which are palpable and pathognomonic if bilateral. About $80 \%$ of patients with VHL disease have a positive family history.

\section{Diagnosis and management}

Retinal haemangioblastomas are diagnosed by indirect ophthalmoscopy. Sporadic haemangioblastomas and those associated with VHL disease are clinically indistinguishable. Fluorescein angiography or funduscopy may be helpful in identifying small peripheral angiomas. ${ }^{9}$ Ultrasonography is useful for measuring tumour dimensions and monitoring treatment effects. Optical coherence tomography (OCT) enhances the assessment of maculopathy.

Treatment is determined by the size, number, and location of the haemangioblastomas, as well as any secondary effects. ${ }^{2,3}$ Fibrosed and inactive lesions can be left untreated. Very small, peripheral lesions may also remain dormant if left untreated; however, because of the high risk of progression, they are usually ablated without 
delay. $^{3}$ Tumours with a thickness of up to $1.5 \mathrm{~mm}$ and a greatest basal diameter not exceeding $4 \mathrm{~mm}$ can be treated with laser photocoagulation. Tumours not more than $5 \mathrm{~mm}$ thick usually respond to cryotherapy, although several sessions of treatment may be necessary. Larger tumours usually require radiotherapy, which can consist of plaque brachytherapy, external beam radiotherapy, or proton beam radiotherapy. ${ }^{2}$ Tractional retinal detachment necessitates vitreoretinal surgery (Figures 2 and 3). Several case reports of successful treatment of retinal angiomas with PDT have recently been published. ${ }^{10-12}$ In contrast, intravitreal anti-VEGF therapy is generally disappointing. ${ }^{13}$ Treatment of juxtapapillary angiomas carries a risk of marked visual loss so that asymptomatic tumours are observed without treatment. There are reports of successful treatment with surgical excision, laser photocoagulation, PDT (Figures 4 and 5), and anti-VEGF treatment. ${ }^{4,14,15}$

Multiple retinal haemangioblastomas are diagnostic for VHL disease; however, it must be noted that about $50 \%$ of solitary retinal haemangioblastomas are associated with this syndrome. ${ }^{1,4,16}$ A patient with a retinal angioma should therefore be screened for VHL disease even if there is only a solitary tumour. ${ }^{4}$ Such screening involves physical examination, blood pressure measurement, as well as imaging of the abdomen and brain. Confirmation of the diagnosis depends on the presentation. ${ }^{3}$ If there is a positive history, this diagnosis can be made even if there is only one ocular or systemic tumour consistent with this disease. When the family

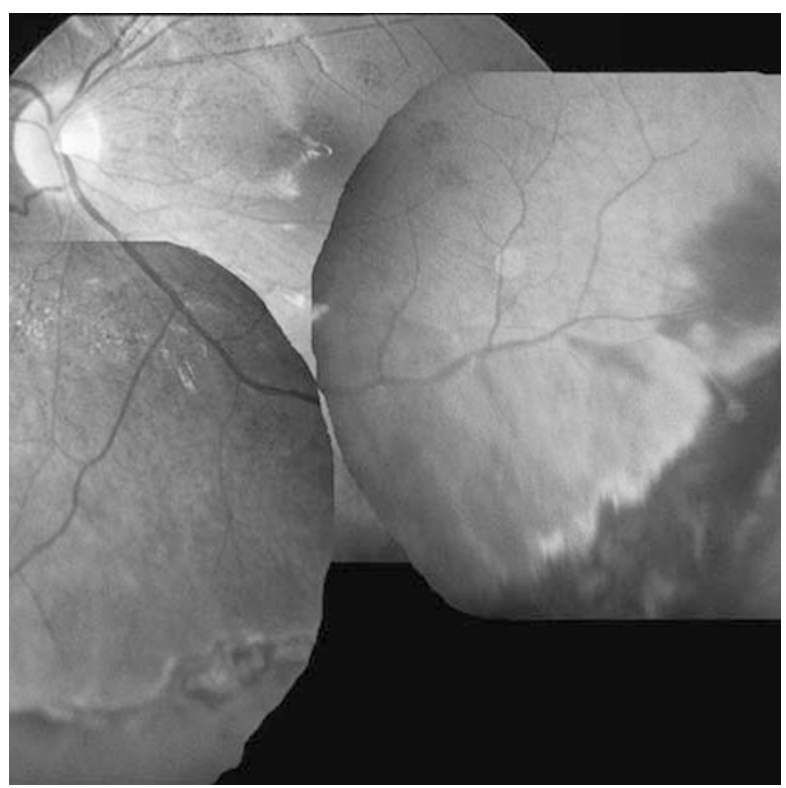

Figure 3 Same patient as in Figure 2. Retinal reattachment following vitrectomy, endoresection, and silicone oil tamponade (courtesy of Prof. N Bornfeld, Essen, Germany). history is negative, the presence of more than one such tumour is sufficient. The diagnosis can be confirmed by detecting a mutation of the VHL gene. ${ }^{3}$ This diagnostic test is particularly important in patients with a solitary retinal haemangioblastoma and a negative family history

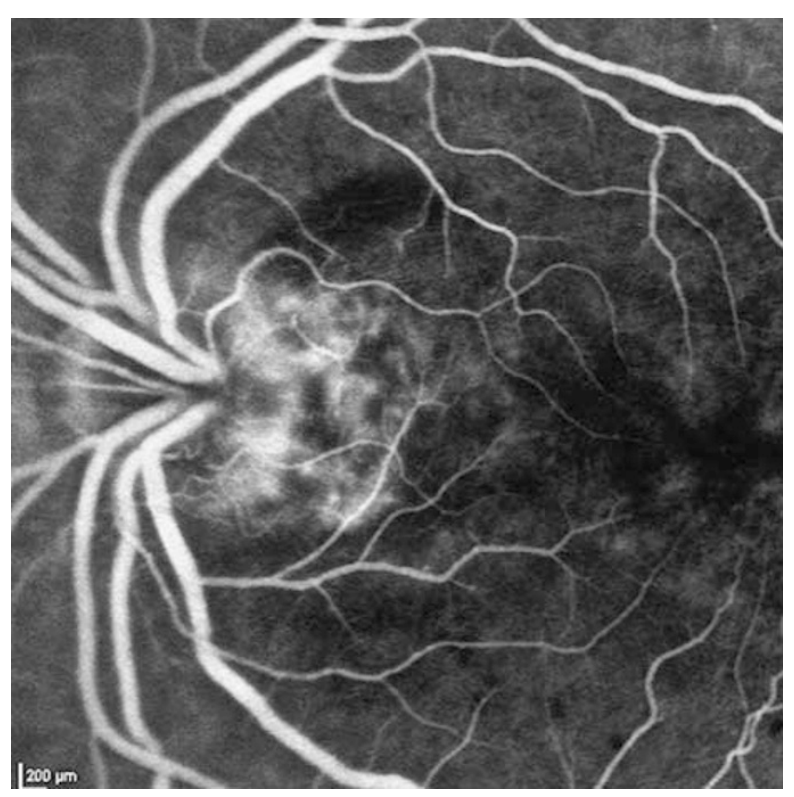

Figure 4 Sporadic sessile retinal haemangioblastoma not associated with von Hippel-Lindau disease. Fluorescein angiography demonstrating leakage from the retinal angioma during the arteriovenous phase. Visual acuity 6/60.

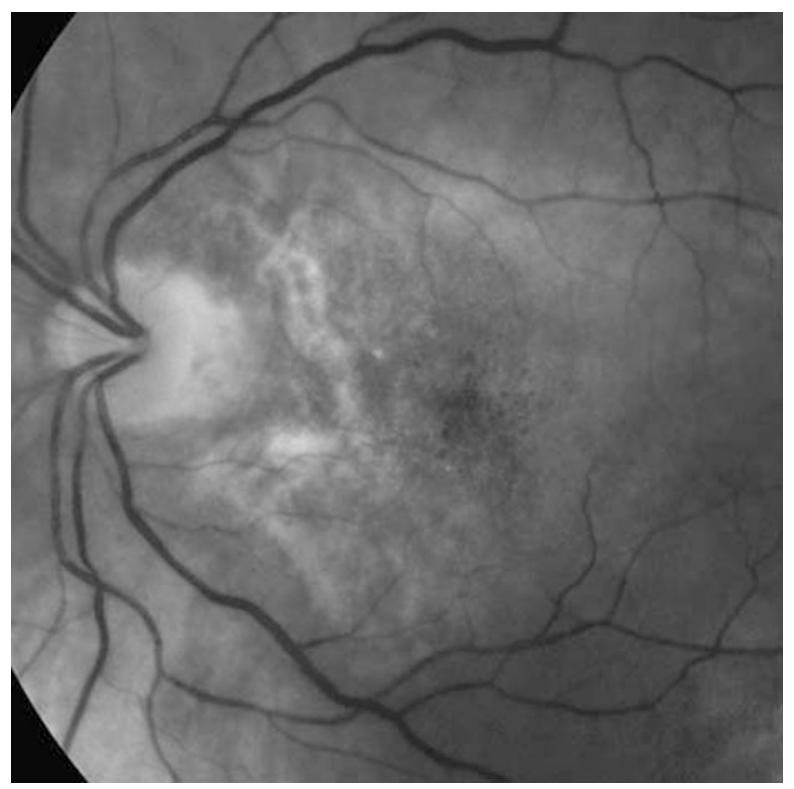

Figure 5 Same patient as in Figure 4. Complete regression of the retinal angioma after one Verteporfin photodynamic therapy using standard parameters. Visual acuity improved to 6/24. 
and in relatives of patients with VHL disease. ${ }^{4,16}$ Some of the sporadic cases may also be caused by a somatic mutation within the VHL gene in the angioma cells, in a similar manner to sporadic retinoblastoma. ${ }^{6}$

Patients with a diagnosis of VHL disease and their relatives should be screened for the disease and other organ manifestations. ${ }^{17}$ Several protocols exist. ${ }^{18}$ Ophthalmological screening should include lifelong annual indirect ophthalmoscopy, starting at pre-school age. $^{9,19}$

\section{Racemose haemangiomatosis}

Racemose haemangiomatosis consists of retinal vascular malformations with anomalous arteriovenous communications and shunts. This condition is categorised as grade 1 if it consists only of an abnormal capillary plexus between the major vessel arcades; grade 2 if one segment of the fundus shows direct arteriovenous communications without interposed capillaries (Figure 6) and grade 3 if massive arterio-venous communications extend throughout the entire fundus. ${ }^{20}$ Grade 1 changes are rarely seen, because they usually remain asymptomatic and are difficult to detect. In the more advanced cases, about $70 \%$ of patients can be classified as grade 2 and about $30 \%$ as grade $3 .{ }^{21}$ Grade 2 and grade 3 changes are almost always associated with cerebral vascular malformations. ${ }^{21,22}$ Massively dilated vessels can be mistaken for angiomatous lesions. The terminology of this condition is confusing, including

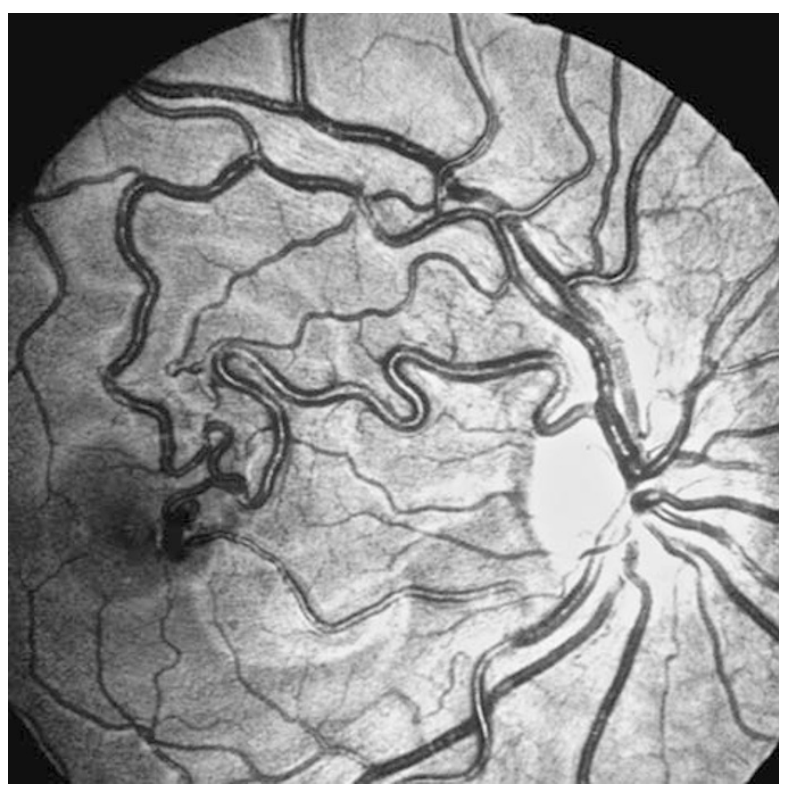

Figure 6 Racemose angiomatosis grade 2. Direct arteriovenous anastomosis without interspersed capillaries (courtesy of Prof. A Wessing, Essen, Germany). nomenclature such as Wyburn-Mason syndrome, Bonnet-Dechaume-Blanc syndrome, and congenital unilateral retinocephalic vascular malformation syndrome (CRC syndrome). ${ }^{21,23}$ The CRC syndrome has been further divided into the 'typical CRC group', consisting of retinal and cerebral arteriovenous malformations with facial vascular skin lesions, and the 'atypical CRC group', without skin lesions.

Racemose haemangiomatosis can be diagnosed at all ages with a mean age of 20 years (range, 4-64). ${ }^{21,23,24}$ Other features include retinal exudates caused by the high blood flow in the arterio-venous communications, retinal and vitreous haemorrhages, retinal venous occlusions, and neovascular glaucoma. Most affected eyes have severe visual loss, caused either by advanced retinal disease or by vascular malformations involving the anterior visual pathway.

\section{Diagnosis and management}

The diagnosis is based on the typical ophthalmoscopic appearances. Fluorescein angiography demonstrates the high-flow arteriovenous communications and adjacent areas of retinal capillary dropout. ${ }^{21,22}$ In most patients, the condition is stable; however, in some cases, the retinal lesions may slowly regress, progress, or affect other areas of the fundus..$^{21,22}$ Some patients show mild, nonpulsatile proptosis. Visual loss can be caused by lesions along the visual pathway, and not by the retinal lesions. A neurological workup is therefore mandatory. Vascular malformations of the jaw can cause severe haemorrhage after dental extraction..$^{25}$ There is no effective treatment. ${ }^{23,24}$

\section{Retinal cavernous haemangioma}

Retinal cavernous haemangioma consists of a cluster of dark-red, saccular aneurysms within the inner retina, often associated with white fibroglial tissue (Figure 7). The condition can occur sporadically or can be inherited in an autosomal dominant manner with invariable penetrance and can be associated with cerebral, spinal, and cutaneous angiomas, and aneurysms..$^{26-31}$ The diagnosis can be made at any age. Secondary changes include epiretinal gliosis and, rarely, retinal and vitreous haemorrhages..$^{30,32,33}$ The angiomas can usually be found away from the posterior pole, so that location at the optic disc or macula is exceptional. ${ }^{30,34}$ Histologically, the telangiectatic vessels forming the angioma show a normal endothelial cell lining. ${ }^{29}$ For this reason, these tumours are not associated with exudation, in contrast to other retinal vascular malformations. 


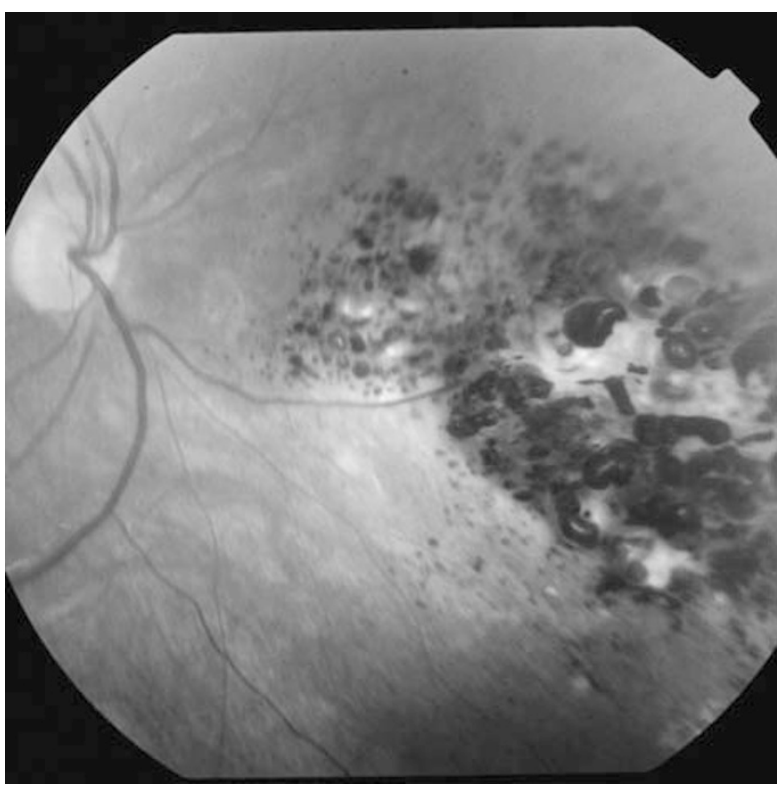

Figure 7 Retinal cavernous haemangioma with epiretinal membrane formation.

\section{Diagnosis and management}

Most cases are incidental findings on routine examination. The diagnosis is established by the typical ophthalmoscopic appearances. Fluorescein angiography typically shows slow filling of the aneurysms with little leakage and late 'capping' of the dye in the superior half of the aneurysms as a result of settling of red blood cells. In addition to demonstrating the aneurysms, OCT may also show an epiretinal membrane. ${ }^{35}$ No treatment is necessary, because these lesions usually remain stable and asymptomatic. ${ }^{36}$ Vitrectomy may be needed if there is a persistent vitreous haemorrhage. ${ }^{32}$ Neurological examination is necessary, because of the known association with cerebral aneurysms. ${ }^{30}$ First-degree relatives should also be examined.

\section{Circumscribed choroidal haemangioma}

Circumscribed choroidal haemangiomas are rare, benign, intraocular tumours, but are not infrequent in tertiary referral centres. ${ }^{37}$ Histologically, these haemangiomas are usually of the cavernous and mixed types, with the capillary haemangiomas being seen only rarely. ${ }^{38}$ Associated changes include degeneration of the overlying choriocapillaris; focal proliferation of the RPE; fibrous metaplasia, and ossification. ${ }^{38}$ Such ossification may clinically resemble an orange pigment.

Choroidal haemangiomas are often mistaken for choroidal metastases and melanomas. ${ }^{37}$ However, an experienced clinician can make a diagnosis by ophthalmoscopy alone, as choroidal haemangiomas have such a characteristic appearance, consisting of an indistinct round-to-oval, pink swelling at the posterior pole, often involving the optic disc, macula, or both. Most tumours are located temporally. Circumscribed choroidal haemangiomas are thought to be congenital hamartomas. ${ }^{37}$ This impression is based on the finding that macular haemangiomas are usually associated with amblyopia, most likely occurring as a result of hypermetropia. Circumscribed choroidal haemangiomas may remain asymptomatic throughout life; however, many patients present between the second and fifth decades with visual symptoms caused by secondary, exudative retinal detachment and macular oedema. ${ }^{37,39}$ Little is known about the natural history of the disease, because most patients presenting to an ophthalmologist are symptomatic and therefore treated. In 17 symptomatic patients who did not undergo treatment, there was no significant growth of the lesion itself but most eyes developed progressive exudative retinal detachment. ${ }^{40}$ Shields $e t ~ a l^{37}$ observed 84 patients and noted such progression in $38 \%$ of cases having a minimum follow-up of 3 months. If left untreated, many such patients will eventually develop severe retinal detachment with secondary glaucoma. ${ }^{38,39}$ Tumour enlargement with increasing exudation has been observed and is believed to represent increasing venous congestion rather than neoplastic cellular proliferation..$^{39,41}$

\section{Diagnosis and management}

The diagnosis can usually be based on the typical clinical ophthalmoscopic appearances (Figure 8).

Ultrasonography shows acoustic solidity with a high internal acoustic reflectivity. In addition, ultrasonography is useful for determining the tumour dimensions, most tumours measuring $4-9 \mathrm{~mm}$ in basal diameter with a thickness of $2-6 \mathrm{~mm} \cdot{ }^{37,42}$ Fluorescein angiography shows a highly vascularised choroidal lesion that typically fills rapidly, simultaneously with the normal choroidal vessels and just before the retinal arteries. ${ }^{37}$ The lesion remains hyperfluorescent throughout the examination. In contrast, indocyanine angiography shows an early, bright flush of dye followed by a characteristic 'washout' of the dye with relative hypofluorescence compared with the adjacent choroid in the late phases of the examination. ${ }^{37,43}$ OCT can identify and quantify any associated macular oedema and is helpful in assessing treatment.

Systemic assessment of patients with circumscribed choroidal haemangioma is not indicated as extraocular manifestations are exceedingly rare, these consisting of 


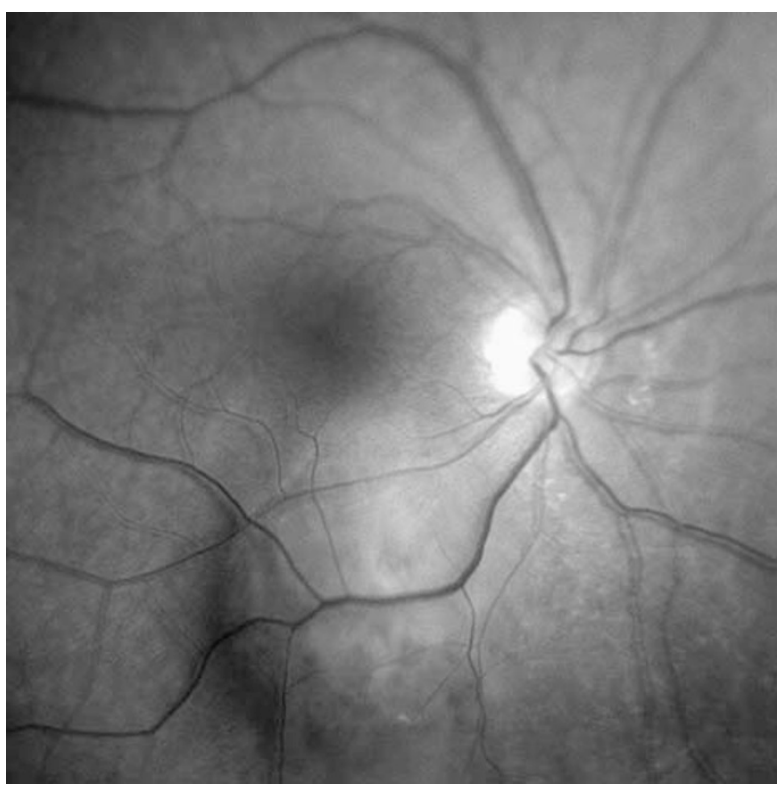

Figure 8 Circumscribed choroidal haemangioma at the posterior pole below the macula and optic nerve head.

Sturge-Weber syndrome, mucosal and cutaneous haemangiomas, and neurofibromatosis. ${ }^{37}$

Asymptomatic patients and those with longstanding visual loss and hence only a small chance of visual improvement are left untreated but kept under observation. ${ }^{37}$ Treatment is recommended for symptomatic patients with exudative retinal detachment and/or macular edema, as well as for patients with severe exudative retinal detachment threatening to cause neovascular glaucoma. PDT is now the preferred treatment in most centres. ${ }^{44-47}$ This yields excellent anatomical and functional results with minimal risk of complications (Figure 9). The exact treatment parameters of PDT are still debated but several authors have recommended bolus injections of Verteporfin, increased application time of laser energy, and overlapping treatment spots. ${ }^{45-47}$ However, over-zealous treatment may cause complications such as RPE atrophy and secondary polypoidal choroidal vasculopathy ${ }^{48,49}$ Recent studies suggest that satisfactory results can be achieved using the same treatment settings as for exudative agerelated macular degeneration (Figure 9) ${ }^{44,48}$ If PDT is not available or is unsuccessful, or if the disease is too advanced, then alternative treatments include transpupillary thermotherapy, external beam, or proton beam radiotherapy. ${ }^{37,50-56}$ Follow-up examinations should include ultrasound measurement of tumour dimensions and OCT examinations of macular oedema, as appropriate. A treatment effect can usually be seen within 6 months. Rarely, repeated PDT is necessary to achieve the desired result. ${ }^{44}$

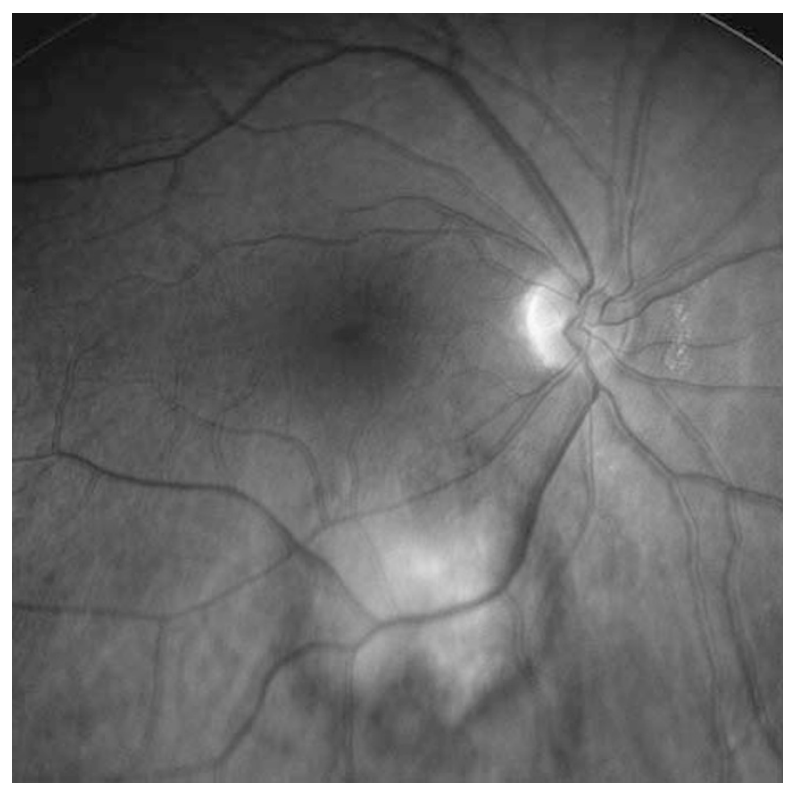

Figure 9 Same patient as in Figure 8. Complete regression of the haemangioma and choroidal atrophy following single Verteporfin photodynamic therapy using standard parameters.

\section{Diffuse choroidal haemangioma}

Diffuse choroidal haemangiomas are sporadic, congenital hamartomas, which are almost always associated with Sturge-Weber syndrome. They may be detected in babies undergoing ophthalmoscopy because of the presence of the typical facial port-wine stain; however, the median age at diagnosis is 5-7 years. ${ }^{57}$ Histologically, these haemangiomas are of the mixed type. In most cases, they are associated with vascular changes of the episcleral and subconjunctival perilimbal tissues, which may explain the high rate of glaucoma. ${ }^{38}$ There may be heterochromia, with increased ipsilateral iris pigmentation. Diffuse choroidal haemangiomas are usually extensive, involving more than half of the choroid, and are usually associated with marked exudative retinal detachment, hypermetropia, and amblyopia.

\section{Diagnosis and management}

In contrast to circumscribed choroidal haemangiomas, diffuse haemangiomas are more difficult to identify and easy to miss on funduscopy (Figure 10). Initially, they are relatively flat, blending with the surrounding choroid so that precise determination of their borders is difficult. Their colour is darker and redder than circumscribed haemangiomas, which tend to be orange-pink. The retinal veins can be dilated and tortuous if the optic disc is compressed by the tumour. B-scan ultrasonography is 


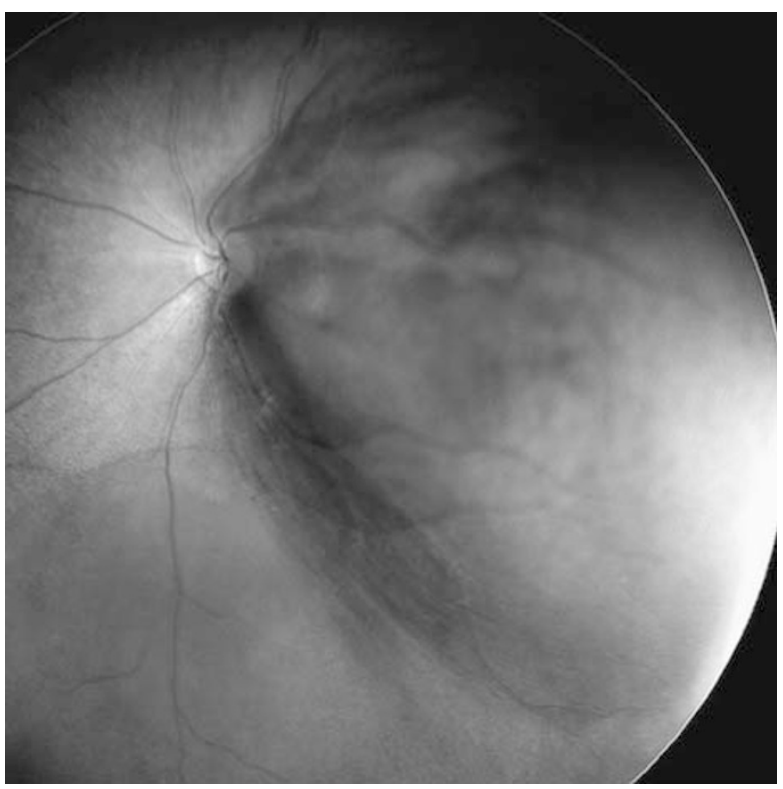

Figure 10 Diffuse choroidal haemangioma with exudative retinal detachment in a 23-year-old female patient with Sturge-Weber syndrome.

helpful in identifying the lesion and demonstrates diffuse thickening of the choroid, with acoustic solidity. There may also be orbital shadowing caused by osseous metaplasia. Fluorescein and ICG angiography findings are the same as those of circumscribed choroidal haemangioma.

Nearly all diffuse choroidal haemangiomas are associated with the Sturge-Weber syndrome, which is a sporadic neurocutaneous disorder characterised by facial capillary malformation (port-wine stain), leptomeningeal angioma, and vascular ocular abnormalities. ${ }^{57}$ Diagnosis of the choroidal haemangioma is usually established during screening in newborns with suspected SturgeWeber syndrome, or in children or young adults with Sturge-Weber syndrome, who develop glaucoma or visual loss as a result of exudation, macular oedema, or increasing hypermetropia. ${ }^{38,58}$

Sturge-Weber syndrome is diagnosed clinically in the presence of the facial cutaneous changes with neurological changes and/or ocular manifestations, which consist of glaucoma in $71 \%$, conjunctival or episcleral haemangiomas in $69 \%$, and diffuse choroidal haemangiomas in $55 \%$ of patients. ${ }^{59}$ Only $8 \%$ of children born with facial port-wine stains are associated with Sturge-Weber syndrome; ${ }^{60}$ however, the association is more common if the facial nevus involves the eyelids. All children with port-wine stains in the area of the trigeminal nerve should, therefore, undergo an anterior segment and dilated fundus examination with measurement of the intraocular pressure and

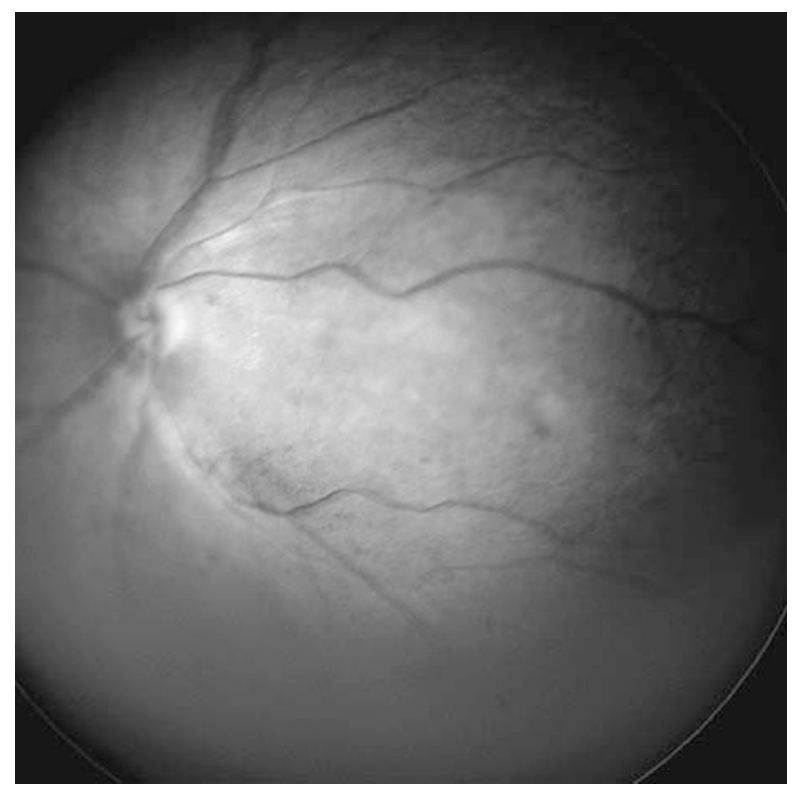

Figure 11 Same patient as in Figure 10. Regression of the diffuse haemangioma and the exudative retinal detachment following Verteporfin photodynamic therapy with standard parameters and four overlapping spots covering the haemangioma at the posterior pole.

ultrasonography to screen for diffuse choroidal haemangioma. ${ }^{57}$ In children with Sturge-Weber syndrome and choroidal haemangioma, leptomeningeal angiomatous lesions are almost always present. ${ }^{57,60}$ Neurological evaluation including contrast MRI should therefore be performed in all children with diffuse choroidal haemangioma. All patients with the SturgeWeber syndrome should also undergo regular screening examinations for glaucoma. Glaucoma develops in infancy in about $60 \%$ of cases and in childhood or early adulthood in $40 \% .^{60}$

Because of the extensive choroidal involvement that is present from birth, the visual prognosis is poor. ${ }^{61,62}$ The main objective of treating diffuse choroidal haemangiomas is to prevent or treat severe retinal detachment, thereby avoiding secondary glaucoma and loss of the eye. ${ }^{61}$ Laser photocoagulation and transpupillary thermotherapy are usually impractical because diffuse choroidal haemangiomas are so extensive and because they are associated with severe exudative retinal detachment. Most cases reported in the literature have therefore been treated with lens-sparing external beam radiotherapy or proton beam radiotherapy. ${ }^{40,50,56,62}$ In about $75 \%$ of patients, regression of the haemangioma and resolution of the secondary exudative retinal detachment can be achieved by these methods; however, a minority of patients develop radiation retinopathy. ${ }^{40,50,62}$ Several reports of successful PDT for diffuse choroidal haemangioma (Figure 11) have 
now been published. ${ }^{63-65}$ These suggest that it is sufficient to treat only the 'active' part of the angioma; that is, the area showing intense fluorescein leakage and overlying secondary RPE degeneration. ${ }^{64}$

\section{Conflict of interest}

The authors declare no conflict of interest.

\section{References}

1 Singh AD, Nouri M, Shields CL, Shields JA, Smith AF. Retinal capillary hemangioma: a comparison of sporadic cases and cases associated with von Hippel-Lindau disease. Ophthalmology 2001; 108(10): 1907-1911.

2 Bornfeld N, Kreusel KM. Capillary hemangioma of the retina in cases of von Hippel-Lindau syndrome. New therapeutic directions. Ophthalmologe 2007; 104(2): 114-118.

3 Junker B, Schmidt D, Agostini HT. Retinal angiomatosis. Ocular manifestation of von Hippel-Lindau disease. Ophthalmologe 2007; 104(2): 107-113.

4 Kreusel KM, Bechrakis NE, Neumann HP, Schmidt D, Foerster MH. Solitary juxtapapillary capillary retinal angioma and von Hippel-Lindau disease. Can J Ophthalmol 2007; 42(2): 251-255.

5 Chan CC, Collins AB, Chew EY. Molecular pathology of eyes with von Hippel-Lindau (VHL) disease: a review. Retina 2007; 27(1): 1-7.

6 Schlesinger T, Appukuttan B, Hwang T, Atchaneeyakasul LO, Chan CC, Zhuang Z et al. Internal en bloc resection and genetic analysis of retinal capillary hemangioblastoma. Arch Ophthalmol 2007; 125(9): 1189-1193.

7 Neumann HP, Cybulla M, Glasker S, Coulin C, Van Velthoven V, Berlis A et al. Von Hippel-Lindau disease. Interdisciplinary patient care. Ophthalmologe 2007; 104(2): 119-126.

8 Latif F, Tory K, Gnarra J, Yao M, Duh FM, Orcutt ML et al. Identification of the von Hippel-Lindau disease tumor suppressor gene. Science 1993; 260(5112): 1317-1320.

9 Kreusel KM, Bechrakis NE, Krause L, Neumann HP, Foerster MH. Retinal angiomatosis in von Hippel-Lindau disease: a longitudinal ophthalmologic study. Ophthalmology 2006; 113(8): 1418-1424.

10 Rodriguez-Coleman H, Spaide RF, Yannuzzi LA. Treatment of angiomatous lesions of the retina with photodynamic therapy. Retina 2002; 22(2): 228-232.

11 Schmidt-Erfurth UM, Kusserow C, Barbazetto IA, Laqua H. Benefits and complications of photodynamic therapy of papillary capillary hemangiomas. Ophthalmology 2002; 109(7): 1256-1266.

12 Wittenberg L, Ma P. Treatment of a von Hippel-Lindau retinal capillary hemangioma with photodynamic therapy. Can J Ophthalmol 2008; 43(5): 605-606.

13 Wong WT, Liang KJ, Hammel K, Coleman HR, Chew EY. Intravitreal ranibizumab therapy for retinal capillary hemangioblastoma related to von Hippel-Lindau disease. Ophthalmology 2008; 115(11): 1957-1964.

14 Kreusel KM, Bechrakis NE, Neumann HP, Foerster MH. Pars plana vitrectomy for juxtapapillary capillary retinal angioma. Am J Ophthalmol 2006; 141(3): 587-589.

15 Ziemssen F, Voelker M, Inhoffen W, Bartz-Schmidt KU, Gelisken F. Combined treatment of a juxtapapillary retinal capillary haemangioma with intravitreal bevacizumab and photodynamic therapy. Eye 2007; 21(8): 1125-1126.

16 Singh A, Shields J, Shields C. Solitary retinal capillary hemangioma: hereditary (von Hippel-Lindau disease) or nonhereditary? Arch Ophthalmol 2001; 119(2): 232-234.

17 Priesemann M, Davies KM, Perry LA, Drake WM, Chew SL, Monson JP et al. Benefits of screening in von Hippel-Lindau disease-comparison of morbidity associated with initial tumours in affected parents and children. Horm Res 2006; 66(1): $1-5$.

18 Maher ER, Yates JR, Harries R, Benjamin C, Harris R, Moore AT et al. Clinical features and natural history of von HippelLindau disease. Q J Med 1990; 77(283): 1151-1163.

19 Moore AT, Maher ER, Rosen P, Gregor Z, Bird AC. Ophthalmological screening for von Hippel-Lindau disease. Eye 1991; 5(Part 6): 723-728.

20 Archer DB, Deutman A, Ernest JT, Krill AE. Arteriovenous communications of the retina. Am J Ophthalmol 1973; 75(2): 224-241.

21 Schmidt D, Pache M, Schumacher M. The congenital unilateral retinocephalic vascular malformation syndrome (Bonnet-Dechaume-Blanc syndrome or Wyburn-Mason syndrome): review of the literature. Surv Ophthalmol 2008; 53(3): 227-249.

22 Wessing A. Congenital arteriovenous communications and Wyburn-Mason syndrome. In: Joussen A, Gardner TW, Kirchhof B, Ryan SJ (eds). Retinal Vascular Disease. SpringerVerlag: Berlin, 2007, pp 535-540.

23 Mansour AM, Walsh JB, Henkind P. Arteriovenous anastomoses of the retina. Ophthalmology 1987; 94(1): 35-40.

24 Patel U, Gupta SC. Wyburn-Mason syndrome. A case report and review of the literature. Neuroradiology 1990; 31(6): 544-546.

25 Hoyt WF, Cameron RB. Racemose angioma of the mandible, face, retina, and brain: report of case. J Oral Surg 1968; 26(9): 596-601.

26 Backhouse $\mathrm{O}, \mathrm{O}^{\prime}$ Neill $\mathrm{D}$. Cavernous haemangioma of retina and skin. Eye 1998; 12(Part 6): 1027-1028.

27 Gass JD. Cavernous hemangioma of the retina. A neurooculo-cutaneous syndrome. Am J Ophthalmol 1971; 71(4): 799-814.

28 Goldberg RE, Pheasant TR, Shields JA. Cavernous hemangioma of the retina. A four-generation pedigree with neurocutaneous manifestations and an example of bilateral retinal involvement. Arch Ophthalmol 1979; 97(12): 2321-2324.

29 Messmer E, Font RL, Laqua H, Hopping W, Naumann GO. Cavernous hemangioma of the retina. Immunohistochemical and ultrastructural observations. Arch Ophthalmol 1984; 102(3): 413-418.

30 Naftchi S, la Cour M. A case of central visual loss in a child due to macular cavernous haemangioma of the retina. Acta Ophthalmol Scand 2002; 80(5): 550-552.

31 Pancurak J, Goldberg MF, Frenkel M, Crowell RM. Cavernous hemangioma of the retina. Genetic and central nervous system involvement. Retina 1985; 5(4): 215-220.

32 Haller JA, Knox DL. Vitrectomy for persistent vitreous hemorrhage from a cavernous hemangioma of the optic disk. Am J Ophthalmol 1993; 116(1): 106-107.

33 Smith BT, Joseph DP. Labor-induced hemorrhage of a retinal cavernous hemangioma. Ophthalmic Surg Lasers Imaging 2009; 40(4): 419-420.

34 Patikulsila D, Visaetsilpanonta S, Sinclair SH, Shields JA. Cavernous hemangioma of the optic disk. Retina 2007; 27(3): 391-392. 
35 Pringle E, Chen S, Rubinstein A, Patel CK, Downes S. Optical coherence tomography in retinal cavernous haemangioma may explain the mechanism of vitreous haemorrhage. Eye 2009; 23(5): 1242-1243.

36 Messmer E, Laqua H, Wessing A, Spitznas M, Weidle E, Ruprecht $\mathrm{K}$ et al. Nine cases of cavernous hemangioma of the retina. Am J Ophthalmol 1983; 95(3): 383-390.

37 Shields CL, Honavar SG, Shields JA, Cater J, Demirci H. Circumscribed choroidal hemangioma: clinical manifestations and factors predictive of visual outcome in 200 consecutive cases. Ophthalmology 2001; 108(12): 2237-2248

38 Witschel H, Font RL. Hemangioma of the choroid. A clinicopathologic study of 71 cases and a review of the literature. Surv Ophthalmol 1976; 20(6): 415-431.

39 Augsburger JJ, Shields JA, Moffat KP. Circumscribed choroidal hemangiomas: long-term visual prognosis. Retina 1981; 1(1): 56-61.

40 Schilling $\mathrm{H}$, Bornfeld N. Long-term results after low-dose ocular irradiation for choroidal hemangiomas. Curr Opin Ophthalmol 1998; 9(3): 51-55.

41 Shields JA, Stephens RF, Eagle Jr RC, Shields CL, De Potter P. Progressive enlargement of a circumscribed choroidal hemangioma. A clinicopathologic correlation. Arch Ophthalmol 1992; 110(9): 1276-1278.

42 Verbeek AM, Koutentakis P, Deutman AF. Circumscribed choroidal hemangioma diagnosed by ultrasonography. A retrospective analysis of 40 cases. Int Ophthalmol 1995; 19(3): 185-189.

43 Schalenbourg A, Piguet B, Zografos L. Indocyanine green angiographic findings in choroidal hemangiomas: a study of 75 cases. Ophthalmologica 2000; 214(4): 246-252.

44 Boixadera A, Garcia-Arumi J, Martinez-Castillo V, Encinas JL, Elizalde J, Blanco-Mateos G et al. Prospective clinical trial evaluating the efficacy of photodynamic therapy for symptomatic circumscribed choroidal hemangioma. Ophthalmology 2009; 116(1): 100-105, e1.

45 Jurklies B, Bornfeld N. The role of photodynamic therapy in the treatment of symptomatic choroidal hemangioma. Graefes Arch Clin Exp Ophthalmol 2005; 243(5): 393-396.

46 Lang GE, Mennel S, Spital G, Wachtlin J, Jurklies B, Heimann $\mathrm{H}$ et al. Different indications of photodynamic therapy in ophthalmology. Klin Monatsbl Augenheilkd 2009; 226(9): 725-739.

47 Michels S, Michels R, Simader C, Schmidt-Erfurth U. Verteporfin therapy for choroidal hemangioma: a long-term follow-up. Retina 2005; 25(6): 697-703.

48 Singh AD, Kaiser PK, Sears JE, Gupta M, Rundle PA, Rennie IG. Photodynamic therapy of circumscribed choroidal haemangioma. Br J Ophthalmol 2004; 88(11): 1414-1418.

49 Tuncer S, Demirci H, Shields CL, Shields JA. Polypoidal choroidal vasculopathy following photodynamic therapy for choroidal hemangioma. Eur J Ophthalmol 2009; 19(1): 159-162.

50 Hocht S, Wachtlin J, Bechrakis NE, Schafer C, Heufelder J, Cordini D et al. Proton or photon irradiation for hemangiomas of the choroid? A retrospective comparison. Int J Radiat Oncol Biol Phys 2006; 66(2): 345-351.

51 Kivela $\mathrm{T}$, Tenhunen M, Joensuu T, Tommila P, Joensuu $\mathrm{H}$, Kouri M. Stereotactic radiotherapy of symptomatic circumscribed choroidal hemangiomas. Ophthalmology 2003; 110(10): 1977-1982.

52 Levy-Gabriel C, Rouic LL, Plancher C, Dendale R, Delacroix $\mathrm{S}$, Asselain $\mathrm{B}$ et al. Long-term results of low-dose proton beam therapy for circumscribed choroidal hemangiomas. Retina 2009; 29(2): 170-175.

53 Lopez-Caballero C, Saornil MA, de Frutos J, Branciotto C, Muinos Y, Almaraz A et al. High dose iodine 125 episcleral brachytherapy for circumscribed choroidal hemangioma. Br J Ophthalmol 2009, [e-pub ahead of print 12 October 2009].

54 Othmane IS, Shields CL, Shields JA, Gunduz K, Mercado G. Circumscribed choroidal hemangioma managed by transpupillary thermotherapy. Arch Ophthalmol 1999; 117(1): 136-137.

55 Rishi P, Sharma T, Chhablani J. Trans-pupillary thermotherapy for circumscribed choroidal hemangioma. Indian J Ophthalmol 2008; 56(1): 84-85; author reply 5.

56 Zografos L, Egger E, Bercher L, Chamot L, Munkel G. Proton beam irradiation of choroidal hemangiomas. Am J Ophthalmol 1998; 126(2): 261-268.

57 Baselga E. Sturge-Weber syndrome. Semin Cutan Med Surg 2004; 23(2): 87-98.

58 Amirikia A, Scott IU, Capo H, Murray TG. Increasing hyperopia and esotropia as the presenting signs of bilateral diffuse choroidal hemangiomas in a patient with SturgeWeber syndrome. J Pediatr Ophthalmol Strabismus 2001; 38(6): 367-368.

59 Sullivan TJ, Clarke MP, Morin JD. The ocular manifestations of the Sturge-Weber syndrome. J Pediatr Ophthalmol Strabismus 1992; 29(6): 349-356.

60 Thomas-Sohl KA, Vaslow DF, Maria BL. Sturge-Weber syndrome: a review. Pediatr Neurol 2004; 30(5): 303-310.

61 Grant LW, Anderson C, Macklis RM, Singh AD. Low dose irradiation for diffuse choroidal hemangioma. Ophthalmic Genet 2008; 29(4): 186-188.

62 Madreperla SA, Hungerford JL, Plowman PN, Laganowski HC, Gregory PT. Choroidal hemangiomas: visual and anatomic results of treatment by photocoagulation or radiation therapy. Ophthalmology 1997; 104(11): 1773-1778; discussion 9 .

63 Anand R. Photodynamic therapy for diffuse choroidal hemangioma associated with Sturge Weber syndrome. Am J Ophthalmol 2003; 136(4): 758-760.

64 Bains HS, Cirino AC, Ticho BH, Jampol LM. Photodynamic therapy using verteporfin for a diffuse choroidal hemangioma in Sturge-Weber syndrome. Retina 2004; 24(1): 152-155.

65 Huiskamp EA, Muskens RP, Ballast A, Hooymans JM. Diffuse choroidal haemangioma in Sturge-Weber syndrome treated with photodynamic therapy under general anaesthesia. Graefes Arch Clin Exp Ophthalmol 2005; 243(7): 727-730. 